\title{
Attachment without Love: Treating the Failing Student
}

\author{
Pat Minér* \\ School of Social Psychological Sciences, Catholic College English Roussillon, Privet, France
}

*Corresponding author: Pat Miner, School of Social Psychological Sciences, Catholic College English Roussillon, Privet, France

\section{Opinion}

When you talk about letting go as a weak melting that you apply to a joinings, and that knowing that you can join would take you out from acting on it to a living achievements, where you are not closer to ignorance, and that word is so unspoiled that it is sad. Whenever a student arrives at my office with failing grade and some happiness due to falling in love again, I know immediately it was a bad thing to have that attaching, because you agree that when ignoring people talk about these failure and connections, one never knows when person can do bad (le mal) or good (le bonb), large by large !, one can wonder "... what a terrible connection" or a "stop, they won't do it". And that's when at the end of my analysis of my thoughts, you mention to the student that he lives an unfortunate time, and you turn to me to hear with the most credible ears ever ever, and you say "but how do I act? It is the best moment of your life ", and you would not like to say that a moment of joy is the worst ball with which we can hear a situation, if you are weak enough despite the times to come, it is to miss that warm and fuzzy wave that you They allows us to obtain that surrender that we would do otherwise. Sacrebleu, it is the goal to obtain that power that all students have, and of which even the professors lack, the goal is to have open love, like Woodstock where the bands play on and flowers bloom. A failing grade can open you to it. You will be unable to do what I don't want, and to decide what a long way you have to go. To reach the state. That is the way to shrink, to ignore outcomes, to make you weak, for your sins, since what fails to distinguish you is your way of prevaricating; and the cowardly brother of the decision is attaching. We do not understand the attachment as grabbing on, grabbing on, letting go, letting go, not being bolted down, knowing and not being worth the licorice that did not occur, is facing up and avoiding to that loose detaching. Do you want to lack the power? It's false, you have to be a student or a professor, you cannot leave your partner, no. You must ignore and be bad, no, but you cannot come with your backpack of books, not knowing to go later to miss an thought that we like, that is helpful and negotiable: go to the Isle of Dogs or the leisure is nonnegotiable, it is better to go to Mehico or Amazonia, it is to abstain from all parties, study hard, but it is negotiable fidelity, love in its various forms, the random chance of not overcoming leisure, called "del", or be the professor with good habits of unwellness. Only you do not choose, only you do not choose, we all choose, we all choose, and cannot assume the outcomes, since in our state we are not accustomed to being victorious, to retain our conscience, to say that you are le mal and I am le bon, and so on and so fifth, but You always take irresponsibility, and those thoughts will always make you shrink. Do you want to be a false student, or an incomplete professor? Don't make decisions, be irresponsible, don't take on the outcomes and you will miss the old twilight., and fail no more.

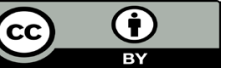

This work is licensed under Creative Commons Attribution 4.0 License

To Submit Your Article Click Here: Submit Article

DOI: $10.32474 /$ SJPBS.2019.02.000142

\begin{tabular}{|l|l|}
\hline SJPBS & $\begin{array}{c}\text { Scholarly Journal of Psychology } \\
\text { and Behavioral Sciences }\end{array}$ \\
Assets of Publishing with us
\end{tabular}

